\title{
Teaching Reform of Electrical Engineering and Its Automation under the Background of Outstanding Engineers
}

\author{
Liu Xiyang* \\ Information and Control Engineering Faculty \\ Shenyang Jianzhu University \\ Shenyang, China \\ e-mail:arnold0110@ sina.com \\ * Corresponding Author \\ Feng Qun \\ Information and Control Engineering Faculty \\ Shenyang Jianzhu University \\ Shenyang China \\ Wang Xin \\ School of Information \& Control Engineering \\ Shenyang Jianzhu University \\ Shenyang China \\ QI Ning \\ The School Library \\ Shenyang Jianzhu University \\ Shenyang China
}

\begin{abstract}
The original major curriculum system and training mode of electrical engineering and its automation is not adapt to the request of the excellence initiative. In order to promote the professional quality and practice ability of electrical engineering and its automation for teachers in higher education institutions, they cultivate excellent engineer, understand the latest education teaching trends, and improve the education teaching ability. Under the background of outstanding engineers, this paper introduces the practice on the training mode, the aim, the curriculum system, the teaching model, the teachers and the other aspects.

In order to adapt to the comprehensive quality and practical ability which enterprises require, the ministry of education proposed "outstanding engineers training plan" in 2010. Excellence program is based on "National medium and longterm education reform and development plan outline (20102020)"and "National medium and long-term talent development plan (2010-2020)", and it is a teaching innovation project for engineering discipline. Electrical engineering and its automation is the third group to open "outstanding engineers' class" which ministry of education approved.
\end{abstract}

Keywords-excellence; formatting; curriculum; styling; insert (key words)

\author{
Kan Fenglong \\ Information and Control Engineering Faculty \\ Shenyang Jianzhu University \\ Shenyang China
}

$\mathrm{Xu} \mathrm{Ke}$

Information and Control Engineering Faculty Shenyang Jianzhu University

Shenyang, China

Kan Hongliang

School of Information \& Control Engineering Shenyang Jianzhu University

Shenyang China

Wang Bin

Northeastern University at Qinhuangdao

Qinhuangdao China

\section{THE ORIGINAL CURRICULUM SYSTEM AND THE PROBLEMS EXISTING IN THE TRAINING MODES.}

A. The curriculum focuses on the theory, and pays the limited attention to the experiment and practice.

The courses divide into basic course, professional basic course and specialized course curriculum. Theory courses include Advanced Mathematics, Probability and Mathematical Statistics, Complex Function, University Physics, Physics Experiment, Basics of Computer Application, Programming Language, Microcomputer Principle and so on. Professional basic courses include Circuit Analysis, Analysis of Circuits Experiment, Digital Electronic Technique, Analog Electronics Technique, Electromechanics, Principle of Automatic Control, Signals and Systems, Electronic Technology, Electrical Measurements, Electric Power Engineering and so on. Above of courses, only Physical Experiment and Circuit Analysis Experiment are separate experiments, the other experiment courses are opened in class. Less course exercises, engineering practice and comprehensive practice training are provided. There is a problem about focusing on teaching and theory, underestimating application and practice.

\section{B. Teaching methods are not flexible enough.}

Theory teaching of teachers is close to the traditional teaching method, there is a lot of cramming system in the 
teaching process. In class, teachers often teach more, students participate in discussions and communication less. Therefore, the classroom atmosphere is depressing and unfavorable to arouse the enthusiasm of students. The single teaching method limits the students' way of thinking and their innovative ability.

\section{Training mode has no advantage to cultivate applied talents in 4 years of university.}

While in this four years, university also opened a experiment for students to simulate the scene, and at the end of each year also arranged for a certain time to enterprise practice. Students can understand the theory and enterprise site better in these experiments and internships. After all, it is a limited time to practice in the enterprise, and it is not really working in the enterprise. Companies don't really make internship students operate something. Students may observe more and operate less. Most importantly, not really working in the enterprise can't be realized the environment.

\section{Less considering that the students experience science- humanities division in high school.}

Students whose major is electrical engineering and its automation are all science students, so they are short of literacy. In stage 4 years study in university, less of the humanities and social sciences courses, just like Management and Finance, can be arranged except ideology and politics courses. It is unfavorable to cultivate engineering and technical students.

\section{E. The practice and the international quality of teachers needs to be improved.}

Almost all the teachers in the university are academics, they come from college to college, and they don' $t$ have enterprises working experience and practical experience. So it is very difficult for the teachers who don' $t$ have a lot of practical experience to combine theory with practice. In the teachers, few of them return from abroad, proportion of the teachers who have overseas experience is also very small. It is hardly conducive to outstanding internationalization requirements of the plan in such conditions.

\section{TRAINING GOALS OF ELECTRICAL ENGINEERING AND ITS AUTOMATION UNDER THE BACKGROUND OF EXCELLENCE ENGINEERS}

Excellence engineers plan is a kind of teaching reform constitutionally, it is a comprehensive reform for teaching of education major, and it is also a operational systems engineering. On one hand, it involves the reform of the current training scheme, training mode, course system, teaching model, teaching method and so on. On the other hand, it refers to the reform of faculty. Two aspects of reform conduct at the same time, it can achieve the goal to cultivate applied and innovative talents.

This major needs to cultivate the students who satisfy the needs of the development of modern science and technology and economic construction. They have a sound personality, good humanistic attainment and moral cultivation, they own the broad natural science foundation, strong electrical engineering foundation and professional skills. They are rich in innovative spirit and strong ability in engineering practice. They can show their strong communication and team cooperation ability. They can work on engineering design, system analysis, information processing, scientific experiment, research and development, economy or science and technology management in the area of electrical engineering or related major, just like system operation, automatic control, industrial process control, electric system, electric machines and electric apparatus, power electronic technology, detection and automation instrument, electronics and computer application.

Cultivating goal can summarize as the following five items:

1) They must have the sound personality, the good humanistic attainment and moral cultivation.

2) They need to have the broad natural science foundation, the strong foundation of electrical engineering and professional skills.

3) They own the innovative spirit, the strong ability in engineering practice.

4) They have the strong communication and the team cooperation ability.

5) Be qualified for technology and economic management position in the field of electric engineering.

The training requirements show as follows:

1) Knowledge: Grasp the broad natural science foundation, master theoretical knowledge, just like Circuit Theory, Principle of Electromagnetic Field, Analog and Digital Electronic Technology, Principle of Automatic control, Fundamentals of Computer Technology, Signal Analysis and Processing.

2) Capability requirement: Grasp the method of the analysis and experiments of system and equipment, the basic ways of science and technology development and engineering design. Have the ability of analyzing, designing, developing about electronic information and electrical engineering.

3) Engineering requirements: Receive the basic training of circuit technique, electronic technique, application of computer technology and network, scientific research and engineering design. Understand the guidelines, policies, laws and regulations of the country about production, design, research and development, environmental protection in the field of electrical engineering and its automatization specialty.

\section{TEACHING REFORM OF ELECTRICAL ENGINEERING AND ITS AUTOMATION UNDER THE BACKGROUND OF EXCELLENCE ENGINEERS}

\section{A. Optimize the curriculum system and strengthen courses integration}

Curriculum system is the baton of teaching. The traditional electrical engineering education in colleges and universities has the problem about inconsistent curriculum structure, being lack of cohesion between courses. These problems make the students have no professional knowledge system. But if you want to pass the exam of register electrical engineer, you must have strong professional and comprehensive abilities. In order to adapt the requirement of the registered electrical engineer, electrical engineering curriculum system of college should 
establish the curriculum system based on professional theory, and strengthen professional skills to improve the comprehensive professional practice ability of students. Integrate different courses in the whole system of the electrical engineering discipline, combine the knowledge with each other, and then adapt to the requirement of electrical engineering comprehensive ability in the actual engineering.

In order to achieve the goal to train outstanding engineers and the comprehensive and innovative talents, according to the current situation, reform the curriculum system, optimize the content of course, and conduct a series of exploration and practice of the curriculum system under the background of Excellence Program. According to the actual, the professional curriculum system of electrical engineering and its automation can be divided into the following several modules: Classroom teaching module, the centralized teaching practice and graduation design module and so on. Classroom teaching module includes the compulsory courses and elective courses. Changes in the course system are mainly manifested in the following respects.

1) Strengthen the importance of practice. Set in the teaching practice in the course system, strengthen and highlight the cultivation of the students' practical ability. Practice form includes both the practice in the campus and the enterprise practice on the outside. The time and the content of practice have improved greatly than it is in the past.

2) Optimize the existing curriculum system. Optimize the experiments for the core courses of electrical engineering and its automation, just like Circuit Analysis, Digital Electronic Technique, Analog Electronics Technique, with increasing the total number of experiments and adding the experiments to improve participate practical activities of the students.

3) Add the courses about humanity and management. Excellence engineers are the personnel who have the high quality, comprehensive and technical accomplishment .The new courses are College Students' Psychology, technological economics, management, students can learn some capacity of management, communication and coordination.

4) Increase the innovative curriculum. Excellence engineer is a kind of innovative technical personnel. It must cultivate their innovation from theory and practice.

5) Show the trend of professional development in the design of course system. Add the courses, such as Solar Energy Generation Technology, Wind Power Technique, Smart Power Grids, Petroleum and Petrochemical Electrical Energy Saving Technology.

6) The reform of the graduation design. The graduation design must refer to the enterprise practice, and conduct the "Double Tutors" system. One of the tutors is a local tutor, the content of graduation design must be combined with the enterprise actual and engineering practice when students select the topics. When students reply, they take part in the college-business reply.

\section{B. The dynamic development of teaching content.}

Teaching of electrical engineering courses must absorb the latest theory and method, focus on the latest results of practice, and then supply it to the teaching, make the teaching content and the actual mix together, make the basic theory be consistent with social development, in case that theory and the practice come apart.

\section{Improve the teaching methods, update the teaching means, pay attention to cultivate students' comprehensive abilities.}

Not only use a variety of modernized teaching means, but also conduct the teaching methods which can improve the students' innovative thinking replace the inject teaching method. Use scientific teaching methods such as "overturn class". Teachers need to prepare every lesson carefully, pay attention to play to the initiative of the students, and focus on cultivating the students' ability of innovation.

\section{CONCLUSIONS}

If electrical engineering teaching reform only aim to cultivate a registered electrical engineer, and the teaching content confines to the examination of registered electrical engineer, it will make that students can't satisfy the needs of social diversity, and then it will happen employment difficulties to students. At the same time, electrical engineering graduates who have worked a certain year are allowed to sign up for the examination of registered electrical engineer. So electrical engineering reform of colleges and universities reaches the requirements for the registered electrical engineer, it also should pay attention to teach students work in all possible areas. Only if it can satisfy the social requirement that electrical engineering graduates must have, and cultivate electrical engineering talent in a broad sense.

\section{REFERENCES}

[1] Markus Hennig, Bärbel Mertsching, Frederic Hilkenmeier, "Situated mathematics teaching within electrical engineering courses". European Journal of Engineering Education, vol. 40 (6), pp. 683-701, 2015

[2] Wang Xin,Guo Lili,Ma Lina. Cooperative Spectrum Sensing Algorithm Based on Second User Selection and Random Forest Classification[J].ICIC Express Letters, Part B: Applications,2015, 6(3):845-850.

[3] O. A. Vlasov, "Improvement of Electrical Engineering Periclase Powder Quality". Refractories and Industrial Ceramics, vol. 53 (6), pp. 384-386, 2013

[4] Bhuyan, Muhibul Haque, Khan, "Teaching a numerical analysis course for electrical engineering students in the cognitive domain". International Journal of Electrical Engineering Education, vol. 51 (1), pp. 82-92, 2014

[5] Gao Xin, Xu Limei, Wang Yu, "The Study of Curriculum System for Electrical Engineering and Automation "Excellent Engineers Training Plan". Advances in Education, vol. 02 (02) pp. 30-35, 2012

[6] ShengWei Mei, Jin Ma, Wang Yu, "New research advancement in electrical engineering field of China-Reviews on special issue of Science in China Series E: Technological Sciences". Chinese Science Bulletin, vol. 54 (8) pp. 1285-1286, 2009.

[7] Huan Chen, Zhenhua Tan, Guangming Yang, Wang Yu, "Discussion on "Outstanding Engineers" Training Program for Information Security Major in China”. IERI Procedia, vol. 2 pp. 868-872, 2012.

[8] KeithK C Chan, "The HKIE Outstanding Paper Award for Young Engineers/Researchers 2011". HKIE Transactions, vol. 18 (4) pp. $1-1,2011$ 
[9] Wang Xin, Huang Kuan, Gao Zhijun. The Primary Users' Signals Recognition Algorithm in Cognitive Radio Networks via KPCA and Random Forest[J].ICIC Express Letters,2015, 9(4):1083-1088.

[10] Qin Jie, Lin Liangzhen, Qi Zhiping, "Progress of Journal "Advanced Technology of Electrical Engineering and Energy" Advanced Technology of Electrical Engineering and Energy, vol. 28 (2) , pp. 78-80, 2009.
[11] Gao Youhua, Zhai Huiping, Shao Ping, "Reformation of Electrical Engineering Curriculum System Orienting to Cultivation of Outstanding Engineers" Advanced Technology of Electrical Engineering and Energy, pp. 74-76, 2012. 